\title{
ESRA8-0359 \\ ULTRASOUND-GUIDED QUADRATUS LUMBORUM BLOCK: AN EFFECTIVE METHOD FOR POSTOPERATIVE ANALGESIA IN OPEN PYELOPLASTY
}

\author{
P. Scimia1, C. Giordano1, E. Basso Ricci1, D. Nicolotti1, S. Di Carlo2, P. Fusco3.
}

1 Hospital of Cremona, Department of Anesthesia and Intensive Care Unit, Cremona, Italy. 2University of Chieti, Department of Anesthesia- Resuscitation- Intensive and Pain Care, L'Aquila, Italy. 3San Salvatore Academic Hospital, Department of Anesthesia and Intensive Care Unit, L'Aquila, Italy.

\section{Background and Aims:}

Anderson-Hynes open pyeloplasty (AHP) is a surgical technique for the management of uretero-pelvic junction obstruction (UPJO). In standard AHP, surgeon generally performs the opening of posterior abdominal muscles and detachment of parirenal fat. The large muscle cutting incision is the major cause of significant postoperative pain. Recent evidences suggested that Quadratus lumborum block type 1 (US-QLB 1) could provide effective postoperative analgesia in urological surgery. To test this hypothesis, we described a 52 year old man, ASA 2, who underwent AHP for treatment of a left UPOJ with severe hydronephrosis (grade IV).

\section{Methods:}

After induction of anesthesia with the patient in a right lateral position, we performed US-QLB 1 by injecting $20 \mathrm{ml}$ of $0,5 \%$ Ropivacaine plus Dexamethasone $4 \mathrm{mg}$ through a 22 gauge $80 \mathrm{~mm}$ needle in the fascial plane between the posterior edge of the transversus abdominis muscle, the quadratus lumborum muscle (QLM) and the underlying transversalis fascia (TF). We ultrasonically confirmed the spread of local anesthetic (LA) over the anterolateral surface of QLM and downward displacement of the retroperitoneal fat. Before the end of surgery, $1 \mathrm{~g}$ of acetaminophen and Ketorolac $30 \mathrm{mg}$ were intravenously administered.

\section{Results}

Patient remained hemodynamically stable throughout the procedure and reported a prolonged pain relief after surgery, without opioids needing. No discomfort and complications were recorded postoperatively.

\section{Conclusions:}

This case report suggested that US-QLB 1, as part of a multimodal analgesic regimen, could provide long-lasting analgesia for AHP, likely due to a predominant spread of LA deep to TF in the retroperitoneal posterior pararenal space.

\section{Keywords:}

Ultrasound guidance

Quadratus Lumborum Block

Postoperative analgesia

Pyeloplasty

Uretero-pelvic junction obstruction 